\title{
Research on the Curriculum System Construction Plan for Animation Design and Production of Specialty in High Vocational Colleges
}

\author{
Zhenhuan Liu \\ Department of Computer Engineering, Dongguan Polytechnic, \\ Dongguan, Guangdong, 523808 China
}

\begin{abstract}
In this paper, we conduct research on curriculum system construction plan for animation design and production of specialty in high vocational colleges. With the development of animation industry in our country, the existing higher vocational anime education already cannot satisfy the needs of the enterprises. Anime professional teaching reform is imminent. This article stands on the basis of existing animation specialty teaching reform, the analysis summarizes common problems, and proposes the corresponding solution hope to make their efforts to the development of animation education. We insist on teachers in the teaching process, and in the case of the classroom into more comprehensive knowledge, to improve the students' technology at the same time, more to improve students' comprehensive qualities to look for the better education performance.
\end{abstract}

Keywords- Curriculum System Reform, Animation Design, High Vocational Colleges, Specialty.

\section{Introduction}

With the development of the information technology, the animation from form to content has the new breakthrough, including traditional two-dimensional animation to the three dimensional animation, the virtual image to role model, synthetic model and real one with simulation image of breakthrough. Specialized courses for anime difficult challenge facing the dilemma of teaching, one is technology progress to improve the speed of animation manufacture and reduce the cost. Secondly, it is harder is low and fast develops reduced art literacy cultivation [1-2].

Referring to the literature review, the primary challenges and drawbacks of our current animation major could be summarized as the follows. (1) The quality of teachers needs to be strengthened. Due to the particularity of the animation specialty, is very high to the requirement of professional teachers, not only requires teachers to have solid basic skills, the more requires teachers to have rich enterprise of actual combat experience, in the basic process of teaching can lead students to participate in and complete the complete project. (2) The old teaching methods. Most of the teachers in the classroom is still in the traditional teaching method, with the pure theoretical knowledge driving skill operation, is shown in the speak neither vivid, also not practical, led directly to the student is not interested in the learning, can't learn, not learn. The homework decorate can't close to the actual needs of students, or too simple, too complicated, and even had nothing to do with practical application. (3) Professional setting is blurred, professional direction positioning is not clear. Fall within the scope of great art animation specialty, it is based on the digital media, video media, stage, 2D animation, 3D animation, digital virtual system. But since most of the major colleges and universities teachers' quantity and the level are limited, so at the time of professional settings and location and more is to consider the school for the 
professional teachers which are the primary drawbacks [3-4].

Anime that involved in technical ability have the hand-painted, planning, painting works, software realization, distribution and publishing, marketing, such as the design and manufacture of derivatives, we mainly refers to the works before release and publication and its work. Project research, the topic selection, planning, design, implementation and release, etc., aims to form to pen, have answers, first through technology rapid implementation. The combination of creative ability and technical ability to create attract anime products market. Creativity is the premise as technology is to realize the creative means. Because the anime has from pure film and television animation to the consumer goods market, greatly expand the development space. Technical ability, therefore, it not only lies in the application software, the animation design and to estimate the demand of the derivatives and the status quo. In the following figure one, we show the general core techniques of the computer animation major.

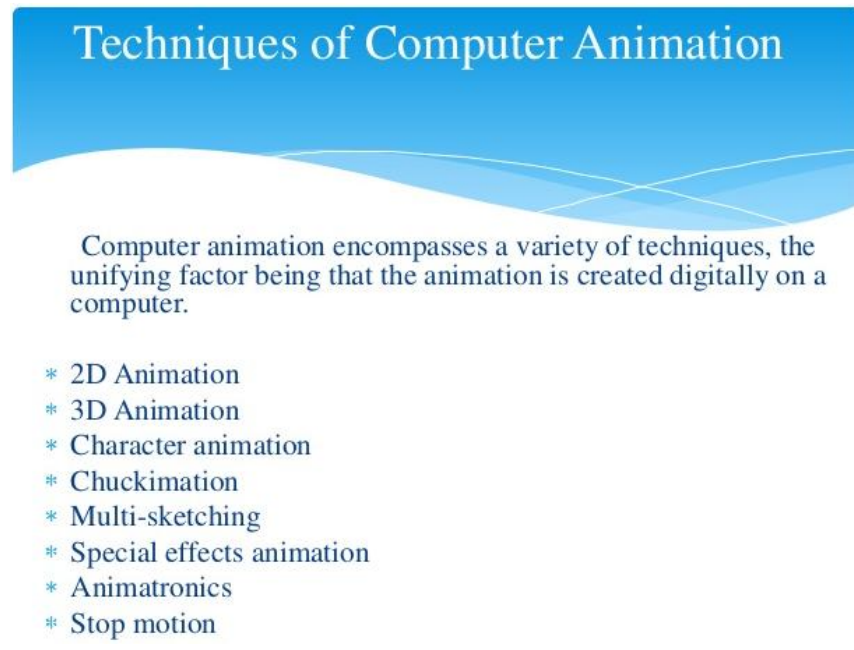

Figure 1. The General Core Techniques of the Computer Animation

In this paper, we conduct research on the curriculum system construction plan for animation design and primary production of specialty in high vocational colleges. Anime culture, animation industry development in China, first of all should be attention to the cultivation of the anime talents, the innovation of the comics, have their own "anime talent" will have their own "comics", a "comics" will be "animation market", formed on to talk about the real "Chinese animation industry". So, cultivating the own animation talent is the most basic link. In recent years, all kinds of colleges and universities across the country have set up animation specialty and cultivate a large number of animation specialty graduates every year. In the later sections, we will propose our perspective on the education reform.

\section{Our Proposed Methodology and Perspective}

The Basic Perspective of College Education Reform. The teaching management is the core of the management of colleges and universities and is to maintain normal operation of teaching order, hub, is to carry out the teaching plan, the implementation of the training objectives and requirements. With the continuous development of science and technology, especially the wide application of computer network technology, gives the mission of the teaching management staff grows increasingly, not only to grasp skilled and flexible use of modern means of the management to make teaching management network, information also constantly updated management concept as make the teaching management standardization, institutionalization 
and scientific. At the same time, to establish and to develop a number of highly qualified and the universities teaching management team as one of the vigorous development of long-term planning [5].

Higher school teaching management work to level, level, as important premise is that the teaching management staff to improve their own quality. Teaching management work for a long time in the first line of teaching management is not only the leadership of staff that is also a link between schools, teachers and students and bridges, work of teachers teaching inspection, examination and evaluation, feedback determines the importance of this work. Under this condition, the general reform orientation of the college education could be summarized as the listed aspects.

- Build efficient classroom and complete knowledge transfer. Teaching is an art, to attract the students to listen attentively, as will arouse their emotions, his teacher must have passion, and use of art, timely use of discussion, humor, questions and so on active classroom atmosphere. Like music struck a chord with a person heart, artistic class can shock the hearts of students and make them impressed by what they have learned content.

- The role of teacher and student to reposition and interaction. The ultimate goal of university education is for the social development and progress of the science and technology to provide high-quality human resources, to achieve both the existing knowledge system of inheritance, and to have function of the innovation and development. Each university has its own school motto, designed to give students a belief and motivation to explore knowledge.

- Pay attention to the training of the students' self-study ability. If the teacher prepares a lesson to consider student's psychological factor, set the teaching content of lively and interesting, and can solve the problem in question and link for students to gain more sense of achievement, it will guide the students' autonomous learning and thinking [6].

The Animation Design Major. Animation design professional has a late start, the characteristics of fast development. We will start from social needs to complete the reform, to establish the teaching direction of employment as the goal, adjust the curriculum, outstanding to the cultivation of students' comprehensive design ability. Therefore, higher vocational education to meet the requirement of the market economy, the professional posts, the higher vocational colleges from the school to find out the employment market demand, according to the requirements of "order training" to promote the reform of the education system. Theoretical teaching, emphasize ability training, to strengthen the teaching of computer aided design, strengthening the role of computer aided design in project design, to meet the needs of talent market which is reflected in the figure 2 . 


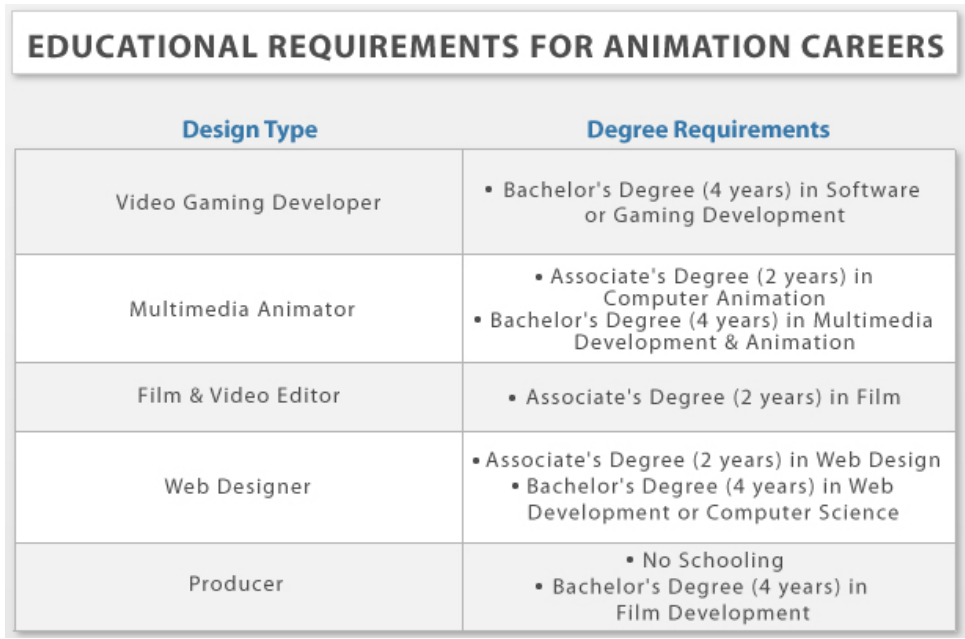

Figure 2. The Characteristics of the Animation Design Major

Nowadays is a popular animation specialty, emerging professional discipline, and its own distinct characteristics, so the inherent and reflects many problems in the traditional teaching mode, such as the teaching mode and the teaching thought conflict is obvious. It is closely related to the animation industry between animation specialties in order to be able to cater to market of commodity economy, the teaching mode of the requirements to the inconsistent [7].

To this degree, we cast our perspectives of the thoughts on animation design major. (1) From the cartoon animation professional content development thinking. The animation specialty construction system must include the content of the fine arts foundation course as software technology and literacy course three categories. Because of good art strength to perfect color collocation, role modelling has decisive role, such as on the display the personality style of animation works and artistic conception has a unique significance. Second, the current animation development process for the project from the traditional pure handmade transition to auxiliary production, computer software that would require animation talent anime master relevant software project development. Third, anime staff should have rich cultural background, animation teaching should pay special attention to training students to find inspiration from traditional culture and folk art, create animation works with national characteristics. (2) Creativity and technology. Too much attention to the cultivation of technology, a large number of only know the computer software operations staff can't be served as director of fine arts, art direction, modelling design creative class work, really achieve the requirements of the enterprise personnel are much rarer. So, the construction of animation specialty should be creative and technology pay equal attention to and to arrange in the curriculum. (3) Professional orientation and training goal. If we want to do a good job in animation specialty, industry standard must be seriously to understand, to carry out market research work for the corresponding jobs to related courses.

The Curriculum System Theory. Curriculum system is to point to in the certain education value concept under the guidance of permutation and combination, the will of course elements are made in the process of dynamic unified point to the target of profession fostering implementation system.

Application-oriented undergraduate cultivation objectives and specifications agreed upon, require the corresponding curriculum system was constructed, therefore should take the local economic and social requirement for application-oriented undergraduate education quality standards as the basis, the fusion related disciplines in the field of knowledge, optimizing 
the curriculum, the reasonable course gate number and period of increase or decrease, so as to build the perfect and reasonable curriculum system. Local undergraduate colleges and basic universities curriculum system is divided into theory teaching course system and practice teaching course system.

By different professional, industry knowledge and skills in the field of curriculum and the campus culture quality course of the activity curriculum modules, in cultivating students' professional skills, technology innovation, quality, at the same time to make the social comprehensive ability of students training, get edify spirit temperament, physical and mental quality has been fully promoted, enabling them to set up the correct outlook on life and values, and form healthy psychology to improve their ability of comprehensive application ability and entrepreneurial innovation.

The Animation Course System. In order to adapt to the demand of the society, better employment oriented, should carry on the direction and modular teaching. The animation specialty is divided into $2 \mathrm{D}$ animation, 3D animation, film and television late direction such as teaching, in order to market demand as the conductor and updated to adjust in a timely manner. At the same time, let the students choose professional direction according to own interests. Teachers collect students' real feedback for professional, and in teaching and research section, the students learned to improve and practice of the integration of professional disciplines on to form a knowledge system has certain characteristics. In the following list, we show our suggestions for the issues.

- University-enterprise cooperation makes joint animation professional talent training scheme. The talent training scheme is in accordance with the specific goal and talent training mode of the talents cultivation, to fairly stable teaching contents and curriculum system, management system and evaluation methods, the process of implementing talent education combined.

- University-enterprise cooperation to build the integration of the cartoon professional training rooms. Because the anime equipment has characteristics of high technical content, updated quickly, animation technology training room construction in vocational colleges should by the enterprise, education experts and frontline teachers common argument, combined with the specialty construction, course construction and comprehensive consideration.

- Animation classes by the university-enterprise cooperation enterprises continued investment, advanced technology and equipment set up the anime integration training rooms, integrating enterprise atmosphere for the students practice environment, can make the teaching meets the demand of society as also make the higher vocational colleges and scientific research of closer to market demand so as to shorten cycle of transformation of scientific research achievements, but also for enterprise reserve technology and talent, shorten the enterprise technology during training for the new recruits.

\section{Conclusion}

In this paper, we conduct research on the curriculum system construction plan for animation design and production of specialty in high vocational colleges. At present, in the opening film and television animation specialty in higher vocational colleges and quite a part of the professional teachers overall relatively weak, it has become one of the most important factors of the quality of the film and the television animation education talent cultivation. At the same time, the film and television animation education in art education, art education is the 
core of creativity, the expression of individuality. In setting up the necessary basic course and specialized course, therefore, at the same time, according to the actual situation of school teaching level, give full play to the advantages of relevant professional teachers and special skills, characteristic courses, to better meet the needs of the students' learning, conveying more excellent talents for the enterprise is necessary. In the future, we will combine more corresponding theories to enhance the current research condition.

\section{References}

[1] Sadler, Philip M., et al. "Stability and volatility of STEM career interest in high school: A gender study." Science Education 96.3 (2012): 411-427.

[2] Balfanz, Robert, et al. "Building a Grad Nation: Progress and Challenge in Ending the High School Dropout Epidemic. Annual Update, 2012." Civic Enterprises (2012).
[3] McGrath, Simon. "Vocational education and training for development: A policy in need of a theory?." International Journal of Educational Development 32.5 (2012): 623-631.

[4] Chong, Eric. "Managerial competencies and career advancement: A comparative study of managers in two countries." Journal of Business Research 66.3 (2013): 345-353.

[5] Ni, Na. "Application and Realization of the Computer Animation Design Based on Improved Cubic B-spline Curves." MATEC Web of Conferences. Vol. 25. EDP Sciences, 2015.

[6] Jianping, Hu. "Canvas Supported Flipped Classroom: the Case of the Course FLASH Animation Design." Distance Education in China 9 (2014): 015.

[7] Song, Huaguang, and Michael Neff. "Design and evaluation of a sketch-based gesture animation tool." Proceedings of the Seventh International Conference on Motion in Games. ACM, 2014. 